\title{
A Caracterização da Bananicultura em São Bento do Sapucaí: Saberes Gastronômicos na Serra da Mantiqueira
}

The characterization of the banana crop in São Bento do Sapucai: Knowledge Gastronomic in the Mountain range

\section{Marília de Moraes Silva}

Centro Universitário Senac Campos do Jordão- Senac - Campos do Jordão - São Paulo - Brasil

\section{Larissa Ramos Botossi}

Centro Universitário Senac Campos do Jordão- Senac - Campos do Jordão - São Paulo - Brasil

\section{Augusto Gardezani Baesso}

Centro Universitário Senac Campos do Jordão- Senac - Campos do Jordão - São Paulo - Brasi

\section{Júlia de Carvalho Freitas}

Centro Universitário Senac Campos do Jordão- Senac - Campos do Jordão - São Paulo - Brasil

Thiago Rosa Zanelatto

Centro Universitário Senac Campos do Jordão- Senac - Campos do Jordão - São Paulo - Brasil

\section{Roseli de Sousa Neto}

Centro Universitário Senac Campos do Jordão- Senac - Campos do Jordão - São Paulo - Brasil

\section{Paula de Oliveira Feliciano}

Centro Universitário Senac Campos do Jordão- Senac - Campos do Jordão - São Paulo - Brasil

\begin{abstract}
Resumo: Conforme se desenvolvem os estudos e tecnologias, cresce o número de pessoas com alcance a informações e, proporcionalmente, se eleva a preocupação com a saúde e o bem-estar físico e mental por meio de uma alimentação mais saudável. Paralelamente a isso, é indispensável praticar uma utilização mais consciente da comida produzida, o que acaba por refletir em progressos econômicos, além da melhor distribuição de alimento à população. Em meio a essa problemática, a filosofia do slow food faz-se ainda mais importante: a valorização do pequeno produtor gera benefícios a todo o ciclo envolvido. A partir desses fatores, enxerga-se um grande potencial na banana, objeto de estudo desta pesquisa. Fruta mundialmente apreciada e largamente produzida, toma-se como foco, no presente caso, a grande produção existente na cidade de São Bento do Sapucaí, no Estado de São Paulo. Dessa forma, pretende-se nesse artigo realizar a caracterização da bananicultura em São Bento do Sapucaí, município localizado na Serra da Mantiqueira paulista. Para esta pesquisa foi realizado levantamento bibliográfico em periódicos disponíveis nas principais bases de dados Scielo, Capes e sítios da internet, utilizando as palavras chaves bananicultura, banana verde e sustentabilidade. Por ser facilmente encontrada e ter preços acessíveis, a banana tem caráter muito versátil para preparações culinárias: uso integral (polpa, casca, flor), em estágios de maturação distintos (verde - como prebiótico - ou maduro) e a partir de variedades como nanica, prata, da terra, maçã, ouro, entre outros. Há também neste conteúdo importância social, uma vez que a divulgação desta pesquisa pode auxiliar na inclusão maior desta fruta mesmo entre as camadas de menor renda da população.
\end{abstract}

Palavras-chave: Bananicultura. Banana verde. Sustentabilidade.

Abstract: As studies and technologies develop and the number of people that reach these information grows, the concern with physical and mental health and well-being through a healthier feeding proportionally raises. In parallel, it's indispensable to practice a moreconscious use of the produced food that reflects in economic progress, besides of a better food distribution to population. Through this problematic, the slow food philosophy shows itself even more important: the valorization of the small 
producer generates benefits in the entire cycle. From these factors, it's seen a great potential in the banana, a fruit that is widely appreciated and extensively produced, focusing, in the present case, in the great production in the city of São Bento do Sapucaí, in São Paulo. Thus, it is intended in this article to characterize the banana crop in São Bento do Sapucai, municipality located in the Serra Mantiqueira. This research was conducted with literature available in major databases Scielo, Capes and websites using the keywords banana plantations, green banana and sustainability. As it is easily found and affordable, banana is a very versatile ingredient for culinary preparations: Full use (pulp, bark, flower) in different maturation stages (green - as prebiotic - or mature) and from its varieties like nanica, ouro, da terra, maçã, prata, among others. There is also a social importance because the disclosure of this research can assist in greater inclusion of this fruit on the diet of low-income population.

Keywords: Banana crop. Green banana. Sustenaibility.

\section{Introdução}

Mundialmente conhecida e consumida, a banana (Musa paradisiaca) é cultivada há mais de 4 mil anos na Ásia e está presente na Europa desde o século I a.C. por intermédio dos romanos; chegou ao Brasil em 1516 trazida pelos portugueses na época das grandes navegações, gerando uma aceitação e consumo tão grandes que viria a se tornar a mais popular fruta aclimatada no País (DELECAVE, 2015). O cultivo mundial da banana está em quarto lugar dentre os produtos agrícolas mais importantes, e, no Brasil, ocupa o segundo lugar no setor da fruticultura. Tem como maiores produtores as regiões Nordeste e Sudeste, com destaque para os Estados da Bahia e São Paulo.

Entretanto, no processo da bananicultura, frequentemente ocorrem perdas consideráveis dessas produções devido a fatores diversos, como baixo nível de organização dos produtores, baixa adoção de tecnologia, pouco acesso a informações da cadeia produtiva, vendas sem diferenciação pela qualidade e perdas pós-colheita (FUNDAÇÃO BANCO DO BRASIL, 2010). Inegavelmente nutritiva, a banana, com todas as suas variações, dentre as mais comuns a banana da terra, a banana maçã, a banana nanica, a banana ouro e a banana prata, possui alto teor energético, é rica em sacarose, frutose, glicose, fibras e sais minerais, como cálcio, ferro, sódio, zinco, potássio, magnésio, fósforo, e vitaminas, como a A, B1, B2 e C; por possuir poucos lipídios é de fácil digestão. Atua ainda como calmante intestinal, estimula a produção de serotonina, melhora a circulação sanguínea e pressão arterial, além de prevenir câimbras (ARAGUAIA, 2015).

No entanto, mais do que o conhecido consumo da fruta madura, in natura ou em suas inúmeras aplicações em diversos pratos, tem ganhado grande foco a utilização da banana verde, na forma de biomassa - um purê feito da polpa cozida - e farinha. Antes de sua maturação, a fruta, além de possuir todos os nutrientes da forma madura, apresenta aspecto de um alimento funcional do tipo prebiótico, ou seja, possui fibras dietéticas solúveis e insolúveis e fruto-oligossacarídeos, cujas ações em nosso organismo seriam, entre outras, a de melhorar a função intestinal, retardar esvaziamento gástrico e diminuir os índices de colesterol sanguíneo (MELLOR, 1984 apud LEON, 2010).

Essa característica funcional da banana verde se mostra graças à presença de amido resistente em sua composição, cuja impossibilidade de quebra pelo sistema digestivo proporciona o fortalecimento e aumento de bactérias boas usadas pela flora intestinal, dificultando a absorção de gorduras e glicose, fato que torna esse um alimento ideal para se inserir na dieta de diabéticos, indivíduos com colesterol alto, que sofrem com prisão de ventre ou 
que estão apenas em busca de uma alimentação saudável (VALLE; CAMARGOS, 2003). Sob a forma de biomassa, a banana verde torna-se um espessante para diversas preparações culinárias, agregando valor nutricional e volume no preparo sem alterar o sabor do alimento.

Como farinha, pode ser uma opção aplicável em substituição à farinha de trigo, tornando os preparos consumíveis a celíacos, indivíduos que não podem ingerir nada que contenha a proteína do glúten. Além disso, a banana, assim como diversas outras frutas, ainda possui a vantagem de poder ser aproveitada integralmente. Pode-se, e até recomenda-se, aproveitar sua casca e flor, muito ricas em fibras, e possuidores de quase $11 \%$ de proteína, $6,3 \%$ de amido e zero de açúcares (VALLE; CAMARGOS, 2003).

\section{HISTÓRICO DA BANANA}

Originária da Índia, Malásia e Filipinas e cultivada há mais de quatro mil anos na China, Filipinas, Assíria, Egito, na região do Mediterrâneo e no Oeste da África, a banana chegou ao Brasil junto aos portugueses, no século XVI, advinda do continente africano. Sua aclimatação no solo brasileiro foi tão intensa que houve quem acreditasse ser ela um fruto indígena. $\mathrm{Na}$ realidade, havia originalmente em terras brasileiras o fruto ao qual chamavam pacoba, a banana-da-terra (Musa paradisíaca), presente sobretudo na região Norte, cujo consumo necessitava de cozimento prévio pelos índios, fazendo às vezes de pão.

No entanto, a maior aceitação e popularização foi mérito da banana vinda das Ilhas de São Tomé, que se tornou tão presente nas plantações brasileiras a ponto de ser considerada a maior contribuição africana para a alimentação do Brasil, em volume, difusão e uso. Era consumida por tribos indígenas, escravos negros e pelos jesuítas recém instalados no Espírito Santo, desempenhando até mesmo papel medicinal (HUE, 2008). À época de sua chegada, era abundante no Nordeste, sobretudo em Pernambuco, onde se atribuiu diversas maneiras de consumo, sendo inclusive exportadas para a Europa após secagem ao sol ou ao lume (CASCUDO, 2011). Atualmente, é uma das frutas mais produzidas em países tropicais e subtropicais do globo.

\section{1 IMPORTÂNCIA SOCIOECONÔMICA}

A banana é a quarta cultura mais importante do planeta, sendo as três primeiras a do arroz, do trigo e do milho (VALLE; CAMARGOS, 2003). A produção global da fruta teve um aumento de 35 milhões de toneladas em 1979 para 95 milhões de toneladas em 2009; dessa produção, a maior parte é destinada ao consumo das populações dos países onde são produzidas (SILVA NETO, 2011). De acordo com dados da FAO (FOOD AND AGRICULTURE ORGANIZATION OF THE UNITED NATIONS) de 2013, o Brasil se encaixa na quarta posição entre os países produtores da fruta, com uma produção de 6.892.622 toneladas, ficando atrás dos 27.575.000 da Índia, 12.370.238 da China e 8.645.749 das Filipinas.

A importância da banana não se limita a simplesmente seu consumo. Seu papel é praticamente social, uma vez que é capaz de alimentar as camadas mais pobres da sociedade devido ao seu baixo custo e constante disponibilidade no mercado. Além disso, é fonte de renda concreta e oportunidade de trabalho aos pequenos e médios produtores de agricultura familiar, os principais responsáveis pela produção no Brasil, graças ao fácil cultivo e manejo, por apresentar uma produção praticamente constante ao longo do ano e por sua grande aceitação no mercado. A fruta é produzida a partir de diversos níveis tecnológicos, desde agricultores altamente tecnificados até aqueles que não fazem uso de tecnologias de plantio e manejo, além de manterem outras culturas como base econômica (FUNDAÇÃO BANCO DO BRASIL, 2010).

O cultivo da banana no Brasil é extenso e ocorre de norte a sul do País, predominantemente na faixa mais próxima ao litoral. $O$ valor de sua produção, de 6.892.622 toneladas em 2013, é apenas ultrapassado pela laranja, no ramo da fruticultura, com 17.549.536 toneladas (FAO, 2013). No entanto, 
frequentemente ocorrem perdas consideráveis devido a fatores diversos, como baixo nível de organização dos produtores, baixa adoção de tecnologia, pouco acesso a informações da cadeia produtiva, vendas sem diferenciação pela qualidade e perdas póscolheita (FUNDAÇÃO BANCO DO BRASIL, 2010) em fevereiro de 2012, produziu-se uma safra de 6.864.055 toneladas em uma área de 496.897 hectares, apresentando, porém, rendimento médio de $14.295 \mathrm{~kg} / \mathrm{ha}$ (IBGE, 2012), demonstrando o baixo aproveitamento da extensa faixa produtiva disponível no País, e justificando a dificuldade do Brasil de inserir esse produto no mercado mundial, mantendo praticamente todo seu consumo ao mercado interno (BORGES; SOUZA, 2004).

Guiada por fatores climáticos, a exploração da banana ocorre principalmente no estado de São Paulo, que responde por $16,5 \%$ da produção, na Bahia, com 13,0\%, Santa Catarina com 10,0\%, Minas Gerais com 8,4\% e o estado do Pará, com 8,1\%. O Rio Grande do Norte é responsável pela maior produtividade, com 31,4 toneladas/ha, sendo 135\% maior que a média do país (13,4t/ha), seguido pelo estado de Santa Catarina com produtividade superior à média brasileira em 64\% e São Paulo, em 54,7\%. Dentro desses estados, as regiões de maior destaque na produção da fruta são o Vale do Ribeira (SP), o Norte de Santa Catarina, o Vale do Submédio São Francisco (PE e BA), o Norte de Minas Gerais e Bom Jesus da Lapa (BA) (EMBRAPA, 2009). A região Sudeste, a segunda maior produtora da banana no Brasil, foi responsável, em fevereiro de 2012, por uma produção de 2.230.345 toneladas, 1.201 .650 advindas do estado de São Paulo (IBGE, 2012). A produção dentro do estado paulista pode ser dividida de acordo com sua distribuição climática. A figura 4 apresenta o mapa da aptidão climática para a cultura da banana no estado de São Paulo.
Figura 1: Mapa do Estado de São Paulo com as faixas climáticas e índices pluviométricos para a cultura da banana *

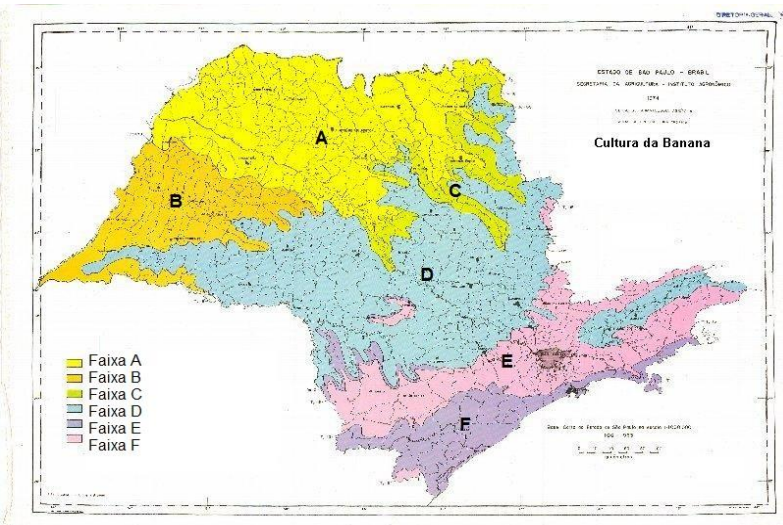

*Legenda complementar

Faixa A: Temperatura média no mês mais frio (Tmf) acima de $18{ }^{\circ} \mathrm{C}$ e condição hídrica anual acima de 80 $\mathrm{mm}$.

Faixa B: Temperatura média no mês mais frio (Tmf) acima de $18{ }^{\circ} \mathrm{C}$ e condição hídrica anual entre 0 e 80 $\mathrm{mm}$.

Faixa C: Temperatura média no mês mais frio (Tmf) entre 15 e $18{ }^{\circ} \mathrm{C}$ e condição hídrica anual acima de 80 $\mathrm{mm}$.

Faixa D: Temperatura média no mês mais frio (Tmf) entre 15 e $18{ }^{\circ} \mathrm{C}$ e condição hídrica anual entre 0 e 80 $\mathrm{mm}$

Faixa E: Temperatura média no mês mais frio (Tmf) entre 15 e $18^{\circ} \mathrm{C}$ e condição hídrica anual igual a zero.

Faixa F: Temperatura média no mês mais frio (Tmf), abaixo de $15^{\circ} \mathrm{C}$, faixa que apresenta deficiência para a cultura comercial da bananeira.

Fonte: Adaptado de ClIAGRO - Centro integrado de informações agrometeorológicas, 2015.

De acordo com o mapa, pode-se compreender as diferentes variedades produzidas em cada área do estado. Segundo informações do CIIAGRO (Centro Integrado de Informações Agrometeorológicas), as variedades maçã e prata são muito resistentes a períodos de seca; no entanto, temperaturas muito baixas, em torno de $10-12^{\circ} \mathrm{C}$, são prejudiciais ao desenvolvimento e qualidade da fruta. A faixa $A$ do mapa não apresenta restrições térmicas, mas exibe uma estação seca bastante pronunciada. É considerada apta para todos os cultivares comercialmente plantados no estado, à exceção daqueles menos resistentes a seca, como a ouro, nanica e nanicão. Abrange a parte mais norte, mais quente do território do estado, o vale do baixo Tietê, todo o rio Grande e as partes baixas dos vales do Turvo, Pardo e Sapucaí Mirim. 
A faixa B apresenta características semelhantes à anterior, apresentando menor deficiência hídrica; dessa forma, a única variedade que não produz é a ouro, pouquíssimo resistente à seca. Essa região está situada no extremo oeste do estado, nos vales do Paraná, Aguapeí, Peixe e Santo Anastácio e baixo Paranapanema. A faixa $C$ só não apresenta aptidão para as variedades mais sujeitas à seca, como ouro, nanica e nanicão. Essa faixa compreende pequenas áreas do planalto em sua parte nordeste.

$\mathrm{Na}$ faixa D, apenas a banana ouro não encontra aptidão. A faixa ocupa grande área do planalto, particularmente a parte central. Na faixa $\mathrm{E}$, por não apresentar muitos períodos de seca, todos os cultivares encontram aptidão climática. A área corresponde à baixada litorânea e ao vale do Ribeira do Iguape. Finalmente, encontra-se na faixa $F$, uma temperatura demasiado fria e, por isso, apresenta deficiência térmica para a cultura comercial da bananeira. Abrange as áreas montanhosas de altitude, das serras do Mar e da Mantiqueira, no sul e leste do estado.

\subsection{Bananicultura em São Bento do Sapucaí e a filosofia Slow Food}

São Bento do Sapucaí é classificada como uma Estância Climática, município de topografia montanhosa, com altitudes entre 920 e 1905 metros (Pedra do Baú) e constitui-se de área de Mata Atlântica e ecossistemas associados. Segundo BRASIL (2000, p. 29 apud RODELA et al, 2014),

O município possui um território de 252,10 km2 e se constitui em inestimável importância ambiental, pois localiza-se na Serra da Mantiqueira, um corredor ecológico muito significativo de Mata Atlântica do Sudeste do Brasil, de prioridade extremamente alta para conservação e uso sustentável"

É importante destacar a forte presença da cidade de São Bento do Sapucaí, localizada a 32 km de Campos do Jordão, com uma extensa bananicultura em nível familiar. Iniciada há cerca de
30 anos na cidade, a produção contribui com o abastecimento de bananas de Campos do Jordão e da Companhia de Entrepostos de Armazéns Gerais de São Paulo, de São José dos Campos e Jacareí, além de participar da produção artesanal do município, feita a partir da fibra de bananeira. Segundo dados do IBGE (2014, apud RODELA et al, 2014), a região se encaixou na 14a posição na produção de banana do estado de São Paulo, em 2012; de 2004 a 2012, a área de bananais aumentou de 900 para 1500 hectares.

Os principais tipos de bananas cultivadas no município são a prata e a nanica, a primeira mais concentrada em áreas de maior altitude e a segunda, em áreas mais baixas. De acordo com os produtores, as plantações da região são livres de fertilizantes ou inseticidas, sendo usados como adubo os restos de poda da própria bananeira (RODELA et al, 2014). A bananicultura da região possui grande destaque, sendo inclusive realizada a Festa da Banana no município, na qual diversas barracas elaboram preparações utilizando a fruta.

A obtenção dos produtos advindos da região de São Bento do Sapucaí condiz com a filosofia do slow food, forte tendência atual na gastronomia. $O$ movimento surgiu em 1986, e tem como conceito básico o direito ao prazer da alimentação, utilizando produtos artesanais de qualidade especial, produzidos de forma que respeite tanto o meio ambiente quanto as pessoas responsáveis pela produção, os produtores. Defende a alimentação consciente e responsável, que proteja a biodiversidade na cadeia alimentar e aproxime os produtores dos consumidores. A filosofia surgiu como uma forma de incentivar o cultivo limpo, tanto para nossa saúde quanto para o meio ambiente e os animais, e os produtores que o realizam dessa forma (SLOW FOOD BRASIL, 2007). Portanto, apoiar os produtores que se esforçam em realizar uma produção com o maior cuidado ao meio ambiente é uma maneira de se inserir na filosofia.

A gastronomia bem informada sobre a agricultura e a ecologia é uma ciência que sabe quais são suas próprias limitações e encontra os recursos 
naturais que garantem um desenvolvimento nas zonas mais ameaçadas do planeta, sem danificar 0 meio ambiente (PETRINI, 2009). Por esse motivo, a sustentabilidade deve estar presente na mentalidade dos gastrônomos em todo o mundo. "A gastronomia sustentável é aquela que se preocupa com as fontes das matérias-primas utilizadas no preparo dos pratos, a fim de diminuir ao máximo os danos ao meio ambiente, contribuindo com 0 desenvolvimento regional" (BAKOS, 2015).

Para adequar a gastronomia ao conceito da sustentabilidade, são necessárias algumas atitudes, enfatizadas por Bakos (2015): optar por alimentos orgânicos, que não façam uso de pesticidas e fertilizantes que afetam o solo e a água; preferir o consumo de ingredientes regionais, que não dependam de transportes poluentes para atravessar longas distâncias; aproveitar produtos da época e não em risco de extinção; evitar o desperdício de alimentos, usando-o ao máximo, para diminuir a produção de resíduos orgânicos; optar por alimentos não processados ou minimamente processados, que não contenham inúmeras embalagens que gerarão lixo inorgânico. Além disso, é essencial atentar-se para o consumo de energia elétrica e água, investindo em tecnologias mais modernas e de menor consumo.

Com a gastronomia sustentável, pode-se beneficiar com a redução de resíduos e gases poluentes lançados na natureza, com a manutenção da biodiversidade, com a ingestão de alimentos mais saudáveis e nutritivos e com a preservação da fauna e da flora.

\subsection{A BANANA- Características da planta}

Pertencente à família Musaceae, o fruto da bananeira é extremamente conhecido no mundo inteiro. É um fruto simples, carnoso, uma baga alongada e trilocular. Seu crescimento ocorre a partir de uma estrutura composta por um falso caule suculento formado pela bainha das folhas e um caule verdadeiro subterrâneo, o rizoma. Possuem flores em cachos que surgem em séries a partir do chamado "coração" da bananeira (MINISTÉRIO DA SAÚDE,
2002). O pseudocaule só produz frutos uma única vez, que são posteriormente cortados. As espécies com inflorescência são polinizadas por morcegos e a falta de sementes é consequência da ausência de polinização e esterilidade, fato que justifica a necessidade de propagação por via vegetativa com intervenção humana, utilizando pedaços de rizoma.

As bananeiras aqui cultivadas são, em sua maioria, híbridas das espécies Musa balbisiana Colla x Musa acuminata Colla (FELIPPE, 2005). Antes de sua maturação, a banana possui cor esverdeada e é composta basicamente por amido e água; no processo de amadurecimento, adquire coloração amarela com manchas marrons e seu amido é transformado em açúcar, glicose e sacarose, garantindo seu característico sabor adocicado (MINISTÉRIO DA SAÚDE, 2002). A figura 2 mostra os diferentes estágios de maturação da banana nanica e a figura 3 ilustra a bananeira com cachos e inflorescência.

Figura 2: Estágios da maturação da banana (Musa paradisíaca L.)

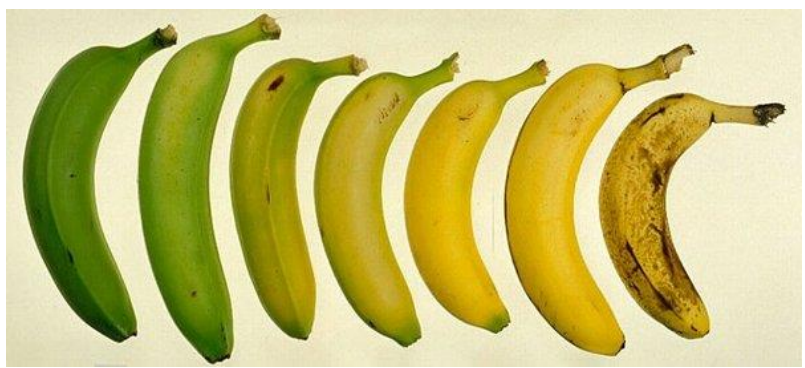

Fonte: CONOCE TU COCINA - BANANA, 2015. 
Figura 3: Bananeira com cacho e inflorescência

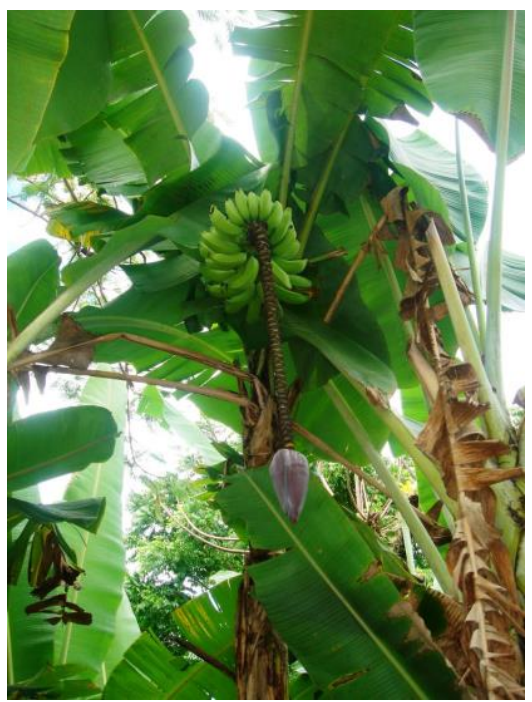

Fonte: PORTAL AGROPECUÁRIO - BANANA E SEU CULTIVO, 2015.

Tem-se conhecimento de uma grande variedade de espécies dentro da gama de bananas cultivadas mundialmente, bem como diversas maneiras de consumo. Em sua literatura, Felippe (2005) divide as mais populares em dois grupos: o das frutas que são comidas cozidas, que se refere à banana-da-terra, e o das que são comidas cruas, abrangendo as variedades nanica, prata, maçã e ouro. A figura 4 traz as diferentes variedades de bananas mais comumente consumidas.

Figura 4: Variedades de banana (Musa paradisíaca L.)

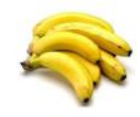

Nanica

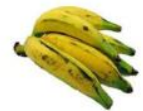

Da Terra

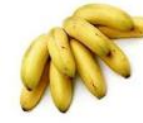

Ouro

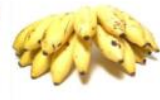

Maşā

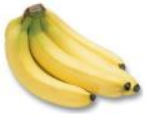

Prata
Fonte: BOM É SER FELIZ, 2015.

A fruta madura possui um alto valor energético, graças ao teor de sacarose, glicose, frutose, amido e fibras, vitaminas tais como A, B1, B2, C, D e E, e minerais como o ferro, potássio. Dessa forma, é responsável por atuar contra diversas enfermidades, como pressão alta, prisão de ventre, depressão, ressaca, câimbras, tensão pré-menstrual, estresse e úlcera (VALLE; CAMARGOS, 2003). A tabela 1 traz a composição nutricional de partes comestíveis de diferentes espécies de banana.

Tabela 1: Composição nutricional por 100 gramas de parte comestível de diferentes espécies de banana

\begin{tabular}{|c|c|c|c|c|c|}
\hline & da terra & maçã & nanica & ouro & Prata \\
\hline umidade (\%) & 63,9 & 75,2 & 73,8 & 68,2 & 71,9 \\
\hline energia (kcal) & 128 & 87 & 92 & 112 & 98 \\
\hline proteína (g) & 1,4 & 1,8 & 1,4 & 1,5 & 1,3 \\
\hline lipídeos (g) & 0,2 & 0,1 & 0,1 & 0,2 & 0,1 \\
\hline colesterol (mg) & NA & NA & NA & NA & NA \\
\hline carboidrato (g) & 33,7 & 22,3 & 23,8 & 29,3 & 26 \\
\hline $\begin{array}{c}\text { fibra alimentar } \\
\text { (g) }\end{array}$ & 1,5 & 2,6 & 1,9 & 2 & 2 \\
\hline cinzas (g) & 0,4 & 0,6 & 0,8 & 0,8 & 0,8 \\
\hline cálcio (mg) & 4 & 3 & 3 & 3 & 8 \\
\hline magnésio (mg) & 24 & 24 & 28 & 28 & 26 \\
\hline $\begin{array}{c}\text { manganês } \\
\text { (mg) }\end{array}$ & 0,16 & 0,6 & 0,14 & 0,09 & 0,42 \\
\hline fósforo (mg) & 23 & 29 & 27 & 22 & 22 \\
\hline ferro (mg) & 0,3 & 0,2 & 0,3 & 0,3 & 0,4 \\
\hline sódio (mg) & $\operatorname{Tr}$ & $\mathrm{Tr}$ & $\mathrm{Tr}$ & $\mathrm{Tr}$ & $\operatorname{Tr}$ \\
\hline potássio (mg) & 328 & 264 & 376 & 355 & 358 \\
\hline cobre $(\mathrm{mg})$ & 0,05 & 0,11 & 0,1 & 0,08 & 0,05 \\
\hline zinco (mg) & 0,2 & 0,1 & 0,2 & 0,3 & 0,1 \\
\hline $\begin{array}{c}\text { vitamina C } \\
(\mathrm{mg})\end{array}$ & 15,7 & 10,5 & 5,9 & 7,6 & 21,6 \\
\hline
\end{tabular}

Fonte: Adaptado de TACO - Tabela Brasileira de Composição de Alimentos, 2011

Como pode-se observar, as diferentes espécies de banana apresentam baixo teor de proteínas, porém alto teor de potássio com exceção da banana maça, e valores traços (tr) de sódio, o que a torna um alimento indicado para dietas restritivas em sódio.

\subsection{Usos culinários}

A banana madura, ou seja, entre os estágios amarelado e com manchas escuras, está entre as frutas com maior possibilidade de aplicações em preparos culinários. Para consumo in natura, basta 
descascá-la e já está pronta para ser consumida. Em preparações, sua variedade da terra é comumente consumida frita, cozida ou na produção de pratos salgados, uma vez que seu sabor não é tão adocicado. As bananas ditas de mesa, como nanica, maçã e prata se fazem presentes em uma vasta gama de preparações, como bolos, compotas, sorvetes, passas, licores, doces e vitaminas.

Seu uso pode variar também conforme a culinária típica de uma dada região: no Rio de Janeiro e em Pernambuco, são incluídas as bananas da terra e nanica no preparo do cozido com carne, tubérculos, legumes e verduras; no sul de Minas Gerais, é especialidade o virado de banana nanica, feito com farinha de milho e queijo mineiro; e, em muitos lugares do Brasil, é misturada a banana nanica ou prata ao diário arroz-e-feijão (CARACTERÍSTICAS DA BANANA, 2015).

\subsection{A BANANA VERDE COMO ALIMENTO PREBIÓTICO}

Antes de sua maturação, quando sua casca ainda possui tom esverdeado, a banana é basicamente composta por amido e água, possuindo no máximo $2 \%$ de açúcares, fato que justifica ser considerada adstringente e até intragável. Com relação aos seus aspectos nutricionais, assemelha-se em alguns valores à forma madura: é rica em vitaminas $A, B 1$, B2, fósforo, potássio, magnésio, manganês, cobre, enxofre, cloro, iodo, ácido nicotínico. (VALLE; CAMARGOS, 2003). A tabela 2 traz a composição química da banana verde e maduras cruas.

Tabela 2: Composição química da banana verde e madura cruas $(100 \mathrm{~g})$

\begin{tabular}{|c|c|c|c|c|c|c|c|}
\hline & $\begin{array}{c}\text { Calorias } \\
\text { kcal }\end{array}$ & Carboidratos (g) & $\begin{array}{l}\text { Proteínas } \\
\text { (g) }\end{array}$ & $\begin{array}{l}\text { Lipídios } \\
\text { (g) }\end{array}$ & $\begin{array}{l}\text { Cálcio } \\
(\mathrm{mg})\end{array}$ & Fósforo (mg) & Ferro (mg) \\
\hline $\begin{array}{c}\text { Banana } \\
\text { verde }\end{array}$ & 122 & 28,7 & 1,4 & 0,2 & 8 & 35 & 0,9 \\
\hline $\begin{array}{c}\text { Banana } \\
\text { madura } \\
\text { (prata) }\end{array}$ & 89 & 22,8 & 1,3 & 0,3 & 15 & 26 & 0,2 \\
\hline
\end{tabular}

Fonte: Adaptado de Franco, 2008.

O grande diferencial da forma imatura da banana com relação à madura está na presença de um carboidrato denominado amido resistente, valor calórico de $122 \mathrm{Kcal}$, além de maior concentração dos minerais ferro e fósforo.

\section{6 $O$ amido resistente como alimento funcional}

Os carboidratos naturalmente presentes nos alimentos podem ser classificados de acordo com o tamanho de sua cadeia e sua classificação nutricional, que está diretamente ligada à digestão. Alguns deles são rapidamente digeríveis, iniciando sua transformação em glicose já na boca; outros são lentamente digeríveis, com a ação enzimática ocorrendo ao longo de todo intestino delgado; e outros, ainda, são resistentes à digestão, sendo fermentados no intestino grosso pelas bactérias que compõem a flora intestinal.

O chamado amido resistente que se apresenta na banana verde se encaixa nesta última classificação, e tem seu papel comparado ao de uma fibra dietética total. Durante a fermentação deste amido, ocorre produção de ácidos graxos de cadeia curta (AGCC), que contribuem para a saúde do cólon, uma vez que inibe o crescimento de células cancerígenas. Por possuir cadeia longa e não ser absorvido no sistema digestivo, provoca aumento do bolo fecal, impedindo, assim, a constipação, diverticulite e hemorroidas, além de diluir compostos tóxicos que formam células cancerígenas.

Ademais, o fato de sua digestão ocorrer de forma lenta contribui para que o nível de açúcar no sangue se eleve de forma gradual, liberando menor quantidade de insulina; dessa forma, esse carboidrato acaba se tornando ideal para dietas de indivíduos 
diabéticos. Por se tratar de uma fibra de características insolúvel e solúvel, contribui também para dificultar a absorção de gordura e para promover maior sensação de saciedade (PEREIRA, 2007).

Dessa forma, a banana verde apresenta aspecto de um alimento funcional do tipo prebiótico, ou seja, possui fibras dietéticas solúveis e insolúveis e fruto-oligossacarídeos (FOS), cujas ações em nosso organismo seriam, entre outras, a de melhorar a função intestinal, retardar esvaziamento gástrico e diminuir os índices de colesterol sanguíneo (MELLOR, 1984 apud LEON, 2010). Os alimentos com características funcionais devem apresentar propriedades benéficas, além das nutricionais básicas como: a capacidade antioxidante, a acidificação do pH intestinal, a interação na redução de citocinas inflamatórias, entre outros (ZAMORA, 2007 apud ALENCAR; SANTOS; FERNANDES, 2014).

\subsection{APROVEITAMENTO INTEGRAL DA BANANEIRA}

Aproveitar integralmente os alimentos consiste em utilizar partes que normalmente são consideradas desprezíveis, como as cascas de frutas, suas flores e folhas. Muitas vezes, pela falta de conhecimento dos elevados princípios nutritivos dos alimentos, ocorre o desperdício de toneladas de recursos. A alimentação integral entra com o preceito de diversificar os alimentos e complementar as refeições (MESA BRASIL SESC, 2003). Este aproveitamento auxilia na redução do desperdício alimentar, na diminuição dos gastos com insumos, bem como na elaboração de novas preparações e aumento do teor nutricional (GONDIM et al, 2005 apud NUNES; BOTELHO, 2009), tendo em vista que, em muitos alimentos, a parte onde se concentra seu maior valor nutritivo está nas cascas, talos, folhas e sementes (BANCO DE ALIMENTOS, 2015).

O aproveitamento integral significa o consumo consciente e sem desperdícios, responsável por evitar a produção excessiva de lixo orgânico, e, assim, auxiliar na redução de chorume e sua consequente degradação dos solos e evitar a proliferação de vetores, como ratos, moscas e baratas (BANCO DE ALIMENTOS, 2015). Além disso, a alimentação integral atua para uma melhor distribuição dos alimentos disponíveis em uma comunidade, possibilitando o acesso desde as camadas mais pobres e contribuindo, assim, para a redução da desnutrição. A banana, assim como diversas outras frutas, possui a vantagem de poder ser aproveitada integralmente. Pode-se aproveitar sua casca e flor, com alto teor de fibras, e possuidores de quase $11 \%$ de proteína, 6,3\% de amido e zero de açúcares (VALLE; CAMARGOS, 2003). Comparativamente à polpa da banana, que seria a parte convencional da fruta, a casca possui $106,6 \%$ a mais de potássio, de acordo com estudos do SESI (2008).

\subsection{Considerações finais}

De maneira ampla, a alimentação está associada como uma necessidade básica e nossas escolhas dependem de fatores que determinam o que, como, com quem, quando e onde comemos, resultando, dessa forma, particularidades que articulam as lógicas culturais das sociedades caracterizando um país, região, grupos, etc. - e delimitam uma cozinha. A disseminação de ingredientes, técnicas, valores, símbolos, receitas por meio da maior circulação de pessoas, imagens e informações acentuaram o conceito de gastronomia.

O estudo aprofundado do objeto de pesquisa deste trabalho, a banana, possibilitou o entendimento de todas as suas propriedades nutricionais, expondo claramente os seus benefícios dentro de uma alimentação saudável e equilibrada. Por ser facilmente encontrada e por preços acessíveis, a banana têm caráter muito versátil para preparações gastronômicas: uso integral (polpa, casca, flor), em estágios de maturação distintos (verde - como prebiótico - ou maduro) e a partir de variedades como nanica, prata, da terra, maçã e ouro. Há também neste conteúdo importância social, uma vez que a divulgação desta pesquisa pode auxiliar na 
inclusão maior desta fruta mesmo entre as camadas de menor renda da população.

Ao chegar ao destino final, o consumidor, os produtos são, em sua maioria, subaproveitados. "O Brasil é um dos países que mais desperdiçam comida" (CHAVES; ANHESINI, 2014). A cultura alimentar brasileira não está acostumada a utilizar os ingredientes em sua totalidade, o que gera um imenso acúmulo de resíduos que voltarão ao meio ambiente, superando sua capacidade de degradação e gerando um agravante com relação à má distribuição de alimentos no mundo. Além disso, o setor gastronômico é responsável por um alto gasto de energia e água.

\section{Referências}

ALENCAR, L. O.; SANTOS, E. D. S.; FERNANDES, A. C. C. F. Desenvolvimento, aceitabilidade e valor nutricional de brigadeiro com biomassa de banana verde. R. Interd. v. 7, n. 4, p. 91-98, out. nov. dez. 2014;

ARAGUAIA, Mariana. Banana. Disponível em $<$ http://www.brasilescola.com/frutas/banana.htm> Acesso em 02 abr. 2015;

BANCO DOS ALIMENTOS. Aproveitamento integral dos alimentos. Disponível em $<$ http://www.bancodealimentos.org.br/alimentacaosust entavel/aproveitamento-integral-dos-alimentos/> Acesso em 19 abr. 2015;

BAKOS, Igor. Sustentabilidade na Gastronomia. Disponível em < http://www.meon.com.br/opiniao/colunas/gastronomia -1/sustentabilidade-na-gastronomia> Acesso em 25 out. 2015

BOM É SER FELIZ. Disponível em $<$ http://www.bomeserfeliz.com.br/2013/10/bolo-debanana-light-e-diet-de-liquidificador/\#> Acesso em 20 abr. 2015;

BORGES, Ana Lúcia; SOUZA, Luciano da Silva (Ed.). O cultivo da bananeira. Cruz das Almas: Embrapa Mandioca e Fruticultura, 2004;

CARACTERÍSTICAS DA BANANA. Disponível em <http://www.jornallivre.com.br/83451/caracteristicasda-banana.html> Acesso em 14 abr. 2015;

CASCUDO, Luís da Câmara. História da Alimentação no Brasil. 4 ed. - São Paulo: Global, 2011;
CHAVES, Guta; ANHESINI, Cinthia. Ingredientes do Brasil. São Paulo. Academia Brasileira de Arte, Cultura e História, 2014;

CIIAGRO - Centro integrado de informações agrometeorológicas. Zoneamento macro - Aptidão ecológica da cultura da banana. Disponível em <http://www.ciiagro.sp.gov.br/znmt_macro_6.html> Acesso em 15 abr. 2015;

CONOCE TU COCINA. Banana. Disponível em <http://www.conocetucocina.com.ar/propiedades/pn0 0777.htm> Acesso em 20 abr. 2015;

DELECAVE, Bruno. A história da banana. Disponível em

http://www.invivo.fiocruz.br/cgi/cgilua.exe/sys/start.ht m?infoid=1075\&query=simple\&search by authornam e=all\&search_by_field=tax\&search_by_keywords=any \&search by priority=all\&search by section $=2 \% 2 \mathrm{C} 9$ $\% 2 \mathrm{C} 8 \% 2 \mathrm{C} 7 \% 2 \mathrm{C} 17 \% 2 \mathrm{C} 99 \% 2 \mathrm{C} 3 \&$ search by state=a II\&search_text_options=all\&sid=7\&text=banana $>$ Acesso em 02 abr. 2015;

EMBRAPA. Sistema de produção da bananeira irrigada. Disponível em <http://sistemasdeproducao.cnptia.embrapa.br/Fontes HTML/Banana/Bananeiralrrigada/mercado.htm> Acesso em 15 abr. 2015;

FAOSTAT - Food and Agriculture Organization of the United Nations. Disponível em <http://faostat3.fao.org/download/Q/QC/E> Acesso em 15 abr. 2015;

FRANCO, G. Tabela de composição química de alimentos. 9a edição, Atheneu, São Paulo, 2008. FELIPPE, Gil. Frutas: sabor à primeira mordida. São Paulo: Editora Senac São Paulo, 2005;

FUNDAÇÃO BANCO DO BRASIL. Desenvolvimento regional sustentável - Fruticultura - Banana. Brasília, v. 3 , set. 2010 ;

HUE, Sheila Moura. Delícias do descobrimento: a gastronomia brasileira no Século XVI. Rio de Janeiro: Jorge Zahar Ed., 2008;

IBGE. Levantamento sistemático de produção agrícola: Pesquisa mensal de previsão e acompanhamento das safras agrícolas no ano civil. Rio de Janeiro, v.25, n.02, p.1-88, fev.2012;

LEON, Tiane Machado de. Elaboração e aceitabilidade de receitas com biomassa de banana verde. UNESC, Criciúma, 2010.

MESA BRASIL SESC - Segurança Alimentar e Nutricional. Banco de Alimentos e Colheita Urbana: Aproveitamento Integral dos Alimentos. Rio de Janeiro: SESC/DN, 2003. Disponível em <http://mesabrasil.sescsp.org.br/media/1016/receitas_ n2.pdf> Acesso em 20 abr. 2015;

MINISTÉRIO DA SAÚDE. BRASIL. Banana. In: Alimentos regionais brasileiros. 1 ed. - Brasília: Ministério da Saúde, 2002. p. 111-112; 
NUNES, Juliana Tavares; BOTELHO, Raquel Braz Assunção. Aproveitamento integral dos alimentos: qualidade nutricional e aceitabilidade das preparações. Brasília, 2009;

PEREIRA, Karla Dellanoce. Amido resistente, a última geração no controle de energia e digestão saudável. Ciênc. Tecnol. Aliment., Campinas, 27(supl.): 88-92, ago. 2007;

PETRINI, Carlo. Slow Food: princípios da nova gastronomia. São Paulo: Editora Senac, 2009.

PORTAL AGROPECUÁRIO. Banana e seu cultivo. Disponível em <http://www.portalagropecuario.com.br/agricultura/fruti cultura/as-vantagens-do-cultivo-de-banana/> Acesso em 20 abr. 2015;

RODELA, Luciana Graci et al. Relações entre bananicultura, artesanato e turismo em São Bento do Sapucaí, SP. Anais do III SINGEP e II S2IS. São Paulo, nov. 2014;

SESI. Tabela de composição química das partes não convencionais dos alimentos. Disponível em $<$ http://bancodealimentos.org.br/wp-

content/uploads/2014/07/Percentual-de-Nutrientescontidos-em-partes-n\%C3\%A3o-convencionais-dosalimentos-em-rela\%C3\%A7\%C3\%A3o-\%C3\%A0parte-convencional.pdf> Acesso em 19 abr. 2015; SILVA NETO, S. P. da; GUIMARÃES, T. G. Evolução da cultura da banana no Brasil e no mundo. Planaltina, DF: Embrapa Cerrados, 2011. Disponível em:

<http://www.cpac.embrapa.br/noticias/artigosmidia/pu blicados/287/>. Acesso em: 13 abr. 2015;

SLOW FOOD BRASIL. Disponível em <http://www.slowfoodbrasil.com/> Acesso em 22 abr. 2015;

TACO - Tabela Brasileira de Composição de $\begin{array}{lccl}\text { Alimentos. Disponível } & \text { em } & < \\ \text { http://www.unicamp.br/nepa/taco/contar/taco } & 4 \text { edica }\end{array}$ o_ampliada_e_revisada.pdf?arquivo=taco_4_versao_ ampliada_e_revisada.pdf > Acesso em 10 abr. 2015;

VALLE, Heloisa de Freitas; CAMARGOS, Marcia. Yes, nós temos banana. São Paulo: Editora Senac. 